\title{
Going against the flow: retention, range limits and invasions in advective environments
}

\author{
James E. Byers ${ }^{1, *}$, James M. Pringle ${ }^{2}$ \\ ${ }^{1}$ Department of Zoology, University of New Hampshire, 46 College Road, Durham, New Hampshire 03824, USA \\ ${ }^{2}$ Department of Earth Sciences, and the Institute of Earth, Oceans, and Space, University of New Hampshire, Durham, \\ New Hampshire 03824, USA
}

\begin{abstract}
Increasing globalization has spread invasive marine organisms, but it is not well understood why some species invade more readily than others. It is also poorly understood how species' range limits are set generally, let alone how anthropogenic climate change may disrupt existing species boundaries. We find a quantitative relationship that determines if a coastal species with a benthic adult stage and planktonic larvae can be retained within its range and invade in the direction opposite that of the mean current experienced by the larvae (i.e. upstream). The derivation of the retention criterion extends prior riparian results to the coastal ocean by formulating the criterion as a function of observable oceanic parameters, focusing on species with obligate benthic adults and planktonic larvae, and quantifying the effects of iteroparity and longevity. By placing the solutions in a coastal context, the retention criterion isolates the role of 3 interacting factors that counteract downstream drift and set or advance the upstream edge of an oceanic species' distribution. First, spawning over several seasons or years enhances retention by increasing the variation in the currents encountered by the larvae. Second, for a given population growth rate, species with a shorter pelagic period are better retained and more able to spread upstream. And third, prodigious larval production improves retention. Long distance downstream dispersal may thus be a byproduct of the many propagules often necessary to ensure local recruitment and persistence of a population in an advective environment.
\end{abstract}

KEY WORDS: Advection · Biogeographic boundaries · Diffusion · Dispersal · Drift paradox · Hemigrapsus sanguineus $\cdot$ Physical-biological coupling $\cdot$ Planktonic larvae $\cdot$ Recruitment

\section{INTRODUCTION}

Many sedentary marine species are dispersed by currents that transport planktonic larval stages. Consequently, the duration of planktonic larval stages is a major determinant of dispersal distances for these species (Strathmann 1980, 1985, Shanks et al. 2003). Thus, simple models of marine dispersal commonly use mean current speed and direction to predict biogeographic boundaries, sources, and sinks of marine populations, and other important spatial patterns in biology. However, if larvae were moved only by the mean currents they would only be transported downstream (downstream is defined here as the direction of the mean current, and upstream is defined as opposite the direction of the mean current, i.e. analogous to stream systems). For an established species to avoid being swept downstream, it must develop a strategy to allow its larvae to be retained against the mean current. In the absence of some mechanism returning larvae upstream against the mean current, the edge of the species range upstream of the mean current will be eroded away as older generations die, and eventually the entire population will be swept downstream and thus become locally extinct. The observed persistence of sedentary adult populations against mean currents is known as the 'drift paradox' (Müller 1982). Because larvae of most benthic marine invertebrates are unable to swim significant horizontal distances, the resolution of this paradox must depend on the upstream dispersal 
of the larvae by stochastic fluctuations of the currents around the mean current.

The balance of mean currents, fluctuating currents, and larval production which allows a population to be retained and to invade upstream is most clearly seen at the upstream edge of the species range. The existing literature has explained the location of species boundaries using 2 seemingly distinct theories. Species boundaries have traditionally been described as the location where the domain becomes uninhabitable, where the species is no longer able to increase its population from low abundance (Caughley et al. 1988). Often, this limit is associated with a temperature dependent increase in mortality of a species (Bird \& Hodkinson 1999, Stachowicz et al. 2002, Crozier 2003). More recently, Gaylord \& Gaines (2000) have demonstrated that many marine species boundaries are located where currents reverse, and propagules are thus constrained by an oceanographic boundary. The theory we derive below unifies these 2 existing theories by demonstrating that both biological and physical factors and their interaction determine where a species can be retained, and thus its range. The 2 existing theories are shown to be endpoints on a continuum of possible population growth and oceanographic conditions that will cause a species boundary to form. Specifically, in a species whose range is not expanding, the upstream edge will often occur at the point where the tendency of mean currents to move the species downstream is exactly balanced by the ability of the species to exploit fluctuating currents to produce and return larvae upstream against the mean current.

Several recent papers have quantified the population growth needed to allow an essentially planktonic species to persist and spread upstream in idealized models of river and stream circulation. Speirs \& Gurney (2001) used a continuous space/time model to find a criterion for the retention of an organism in a stream or estuary. Pachepsky et al. (2005) extend the model of Speirs \& Gurney (2001) by explicitly including benthic and planktonic life phases in a continuous space/time model, and they noted the link between the ability of a population to invade upstream and to be retained. The Pachepsky et al. (2005) model of the interaction of the benthic and planktonic stages is not appropriate for many oceanic species, for in their model benthic adults directly produce benthic offspring, while at the same time some fraction of the adults detach from the benthos and enter the plankton for a well defined time. Neither the Speirs \& Gurney (2001) nor the Pachepsky et al. (2005) models explicitly analyze the retention of iteroparous organisms which can reproduce over multiple generations, and they do not quantitatively address the effects of extended adult lifespan. Spiers \& Gurney (2001) and Pachepsky et al. (2005) also find that the ability of an organism to be retained depends on, among other parameters, the variation of the dispersal distance of offspring from their parents. They represent this variation in terms of a single eddy diffusivity for each location in a stream. It is shown below that this is not always appropriate, that retention in the ocean depends on many forms of variability in the circulation, and that this variability must be calculated on time and space scales relevant to the life history of the organism.

We find criteria for the retention of a population for application to a coastal marine environment similar to that modeled by Largier (2003) and Gaines et al. (2003) using an integro-differential model similar to the analysis of retention by Lutscher et al. (2005). We adapt and extend the Lutscher et al. (2005) model to the coastal ocean using a formalism that easily and naturally incorporates observable physical oceanographic data, including the interannual variability of the currents and multiple spawning events in different seasons. Further, with a simple numerical model we quantify the importance of iteroparity on retention.

Our model suggests adaptations that enable coastal species to be retained and to spread upstream, and clarifies how organisms can modify their larval and spawning behavior to adapt to local oceanographic conditions. The model further suggests how several longstanding life history observations of marine species (e.g. prodigious larval production and multiple or prolonged spawning pulses) can be interpreted as methods to aid retention and upstream dispersal.

We find support for the predictions of our model in an analysis of the timing of planktonic larval release in the northeast Pacific; the majority of larval release times are consistent with a strategy which optimizes the likelihood of species retention. Indeed, recent studies suggest that in general, self-recruitment or local retention may be more common than previously thought in marine populations (Swearer et al. 1999, 2002, Strathmann et al. 2002). We also discuss how the interplay of growth, mean currents, and retention may affect ecological processes with important conservation ramifications, such as the spread of nonindigenous marine species and species' responses to climate change.

\section{MODEL AND RESULTS}

\section{Semelparous species}

We proceed by combining discrete time models of larval dispersal and population growth to predict parameter values that promote upstream dispersal and local retention of larvae in a coastal ocean. In order to make these results more applicable in an oceanic 
environment, we use a formalism that can easily incorporate observations of the coastal currents and larval behavior into the predictions of species invasion and retention in the coastal ocean.

The environment we consider is a coastal habitat of limited cross-shore extent, so the domain can be considered 1-dimensional. The coastline need not be straight, just describable by a single alongshore distance. Our model organisms are assumed to follow the common marine invertebrate life history of having a planktonic larval stage at which most or all of the dispersal occurs. This larval stage remains in the plankton for a time $T_{m}$ before settling. On average, the mean currents cause the larvae released by a mother over an entire generation to recruit a distance $L_{\text {adv }}$ downstream from their mother, though all larvae do not settle at the same distance downstream. Variability in the currents disperse the larvae so that when they settle they are distributed with a standard deviation (SD) of $L_{\text {diff }}$ around the point $L_{\mathrm{adv}}$ downstream of their mother. We emphasize that we do not explicitly specify the spatial distribution of the larvae, though it is assumed that the dispersal kernel is not leptokurtic, which is reasonable in the coastal ocean (Davis 1985, Siegel et al. 2003).

If larvae are released into a coastal ocean whose flow statistics are statistically stationary over the time the larvae are in plankton $\left(T_{m}\right)$, and over the distance they are likely to move $\left(L_{\text {adv }}\right)$, then $L_{\text {adv }}$ and $L_{\text {diff }}$ can be estimated from observable oceanic properties with a simple model of Siegel et al. (2003). Siegel et al. (2003) show that larvae released in a single spawning event in such an ocean move on average a distance:

$$
L_{\text {adv }}=U_{\text {current }} T_{m}
$$

with a random spread around this mean distance specified by:

$$
L_{\text {diff }}=\left(\sigma^{2} \tau_{\mathrm{L}} T_{m}\right)^{0.5}
$$

where $U_{\text {current }}$ is the mean alongshore flow experienced by the larvae, $\sigma$ is the SD of the alongshore currents, and $\tau_{L}$ is the Lagrangian timescale of the fluctuations of the alongshore currents. The $\tau_{L}$ is the timescale of the fluctuations of the currents as experienced by a larva moving with the currents, i.e. along the path a larva takes. All of these parameters are defined at the depth(s) that the larvae reside and only over the time period that larvae are planktonic (Table 1). $U_{\text {current, }} \sigma$ and $\tau_{\mathrm{L}}$ can be observed with standard physical observing tools (Davis 1985) (if the statistics of the ocean currents change significantly over the distance or the time the larvae are in the plankton, then it is necessary to use more complex tools to characterize their $L_{\text {diff }}$ and $L_{\text {adv }}$ perhaps observations made with Lagrangian drifters or floats [e.g. Davis 1985], or particle tracking simulations made in numerical models [e.g. Tilburg et al. 2005]).

\begin{tabular}{|c|c|}
\hline Parameter & Explanation \\
\hline$N_{\text {fec }}$ & $\begin{array}{l}\text { Number of larvae per generation per adult } \\
\text { which would successfully recruit and grow } \\
\text { to reproductive competency in a sparsely } \\
\text { populated environment (i.e. with no density } \\
\text { dependence). This variable is analogous to the } \\
\text { variable } R \text {, the intrinsic rate of population } \\
\text { growth, used in population growth models }\end{array}$ \\
\hline$N_{\text {gen }}$ & $\begin{array}{l}\text { The number of generations an organism } \\
\text { reproduces }\end{array}$ \\
\hline$N_{\text {fec }} \times N_{\text {gen }}$ & $\begin{array}{l}\text { Number of successfully recruiting larvae } \\
\text { produced over an individual's lifetime, in the } \\
\text { absence of density dependence }\end{array}$ \\
\hline$L_{\mathrm{adv}}$ & $\begin{array}{l}\text { Mean distance a larva recruits downstream of } \\
\text { its mother }\end{array}$ \\
\hline$L_{\text {diff }}$ & $\begin{array}{l}\text { SD of distance a larva recruits downstream } \\
\text { of its mother }\end{array}$ \\
\hline$L_{\text {diffeffect }}$ & $\begin{array}{l}\text { Effective value of } L_{\text {diff }} \text { to use in Eqs. (5) \& (6) } \\
\text { when } L_{\text {adv }} \text { undergoes interannual variability; it } \\
\text { is the SD of larval dispersal distance for all lar- } \\
\text { vae released over the lifetime of an individual }\end{array}$ \\
\hline$n$ & Time in units of generations \\
\hline$\sigma$ & $\begin{array}{l}\text { SD of Lagrangian alongshore currents experi- } \\
\text { enced by planktonic larvae }\end{array}$ \\
\hline$\sigma_{L_{\text {adv }}}$ & SD of $L_{\text {adv }}$ when $L_{\text {adv }}$ varies interannually \\
\hline$\tau_{\mathrm{L}}$ & $\begin{array}{l}\text { Lagrangian timescale of alongshore currents } \\
\text { experienced by planktonic larvae }\end{array}$ \\
\hline$T_{m}$ & Time larvae spend in plankton \\
\hline$U_{\text {current }}$ & $\begin{array}{l}\text { Mean alongshore current speed experienced } \\
\text { by larvae in plankton }\end{array}$ \\
\hline
\end{tabular}

Table 1. Defined parameters

A population can be retained in an area, and even move upstream, if the random fluctuations of the currents return enough larvae to the habitat of the adult residents to offset the mortality of the residents. The propagule production is quantified by the parameter $N_{\mathrm{fec}}$ the number of successfully recruiting larvae produced in the single spawning event of a semelparous organism, in a population where density dependent effects are not significant. In this definition, a larva is 'successful' if it recruits and reaches reproductive competency. $N_{\text {fec }}$ is thus net of all mortality in the larval pool and mortality after settlement but before reproductive competence. In the text below, $N_{\text {fec }}$ is referred to as the number of potentially successful larvae, to emphasize that it is the number of larvae that would be successful in the absence of density dependence. In a small, growing population there will be in each generation $N_{\text {fec }}$ times more individuals than the generation before. Thus after $n$ generations, there will be $N_{\mathrm{fec}}^{n}$ individuals. For a semelparous species, $N_{\text {fec }}$ is essentially the same as the discrete intrinsic population growth rate, $R_{\mathrm{i}}$ however, we choose this notation because it makes the analysis of iteroparous populations considerably more straightforward (see next subsection). 
In an advective environment our definition of $N_{\text {fec }}$ may differ subtly from the way $R$ is typically measured by ecologists (e.g. Grosholz 1996). Ecologists estimating $R$ have typically measured the change in population at a location in space relative to the population at that place, an Eulerian definition of population growth. Our $N_{\text {fec }}$ is defined for an adult and its progeny, even as the progeny move (on average) downstream of the location of the mother and thus is a Lagrangian definition. In a non-advective environment, or an environment which does not change in the alongshore direction, these definitions are equivalent. In an advective environment in which the population varies along the shore (e.g. at an invasion front), births and deaths at a point in space can differ dramatically from measurements that track a cohort of larvae as they move on average downstream.

To determine the values of $L_{\mathrm{adv}}, L_{\mathrm{diff}}$, and $N_{\mathrm{fec}}$ which allow retention of a semelparous species, consider a single individual introduced into an empty uniform domain at $y=0$. If the species is retained, the population will grow at the point of introduction, and if the species is not retained, the population will decrease at that point. Each generation after the introduction, the larvae will be displaced on average $L_{\text {adv }} \pm L_{\text {diff }}$ downstream of its parent, so the distribution of individuals at time $n$ will consist of $N_{\text {fec }}^{n}$ instances of a sum of $n$ random steps of mean length $L_{\text {adv }}$ and SD $L_{\text {diff. For a }}$

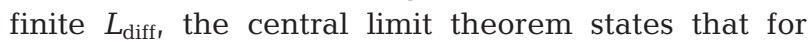
non-leptokurtic dispersal kernels, the adults after $n$ generations will tend to be normally distributed around a location $n L_{\text {adv }}$ downstream, with a SD of the location of the individuals of $n^{1 / 2} L_{\text {diff }}$. Thus, as $n$ becomes large, the density of the individuals per unit length along the shore $P(y)$ will become close to the Gaussian:

$$
P(y)=\frac{N_{\mathrm{fec}}^{n}}{L_{\mathrm{diff}} \sqrt{2 \pi n}} \exp \left\{-\frac{\left(y-n L_{\mathrm{adv}}\right)^{2}}{2 L_{\mathrm{diff}}^{2} n}\right\}
$$

This equation describes a normal distribution whose integral over the entire domain is $N_{\text {fec }}^{n}$, which is the total population. On average, the majority of larvae move downstream, regardless of the choice of parameters, as long as there is a mean current (Fig. 1). However, the population is retained at $y=0$ if the population there remains constant or grows, instead of decreasing to zero. The equation above can be written at $y=0$ as (using the identity $a^{b}=\mathrm{e}^{b \ln a}$ ):

$$
P(0)=\frac{1}{L_{\text {diff }} \sqrt{2 \pi n}} \exp \left\{n\left[\ln \left(N_{\text {fec }}\right)-\frac{L_{\text {adv }}^{2}}{2 L_{\text {diff }}^{2}}\right]\right\}
$$

If the term in the square bracket is $>0$, the population grows at $y=0$ and upstream, and if $<0$, the population at $y=0$ and upstream goes rapidly to 0 . Thus, the species will be retained if
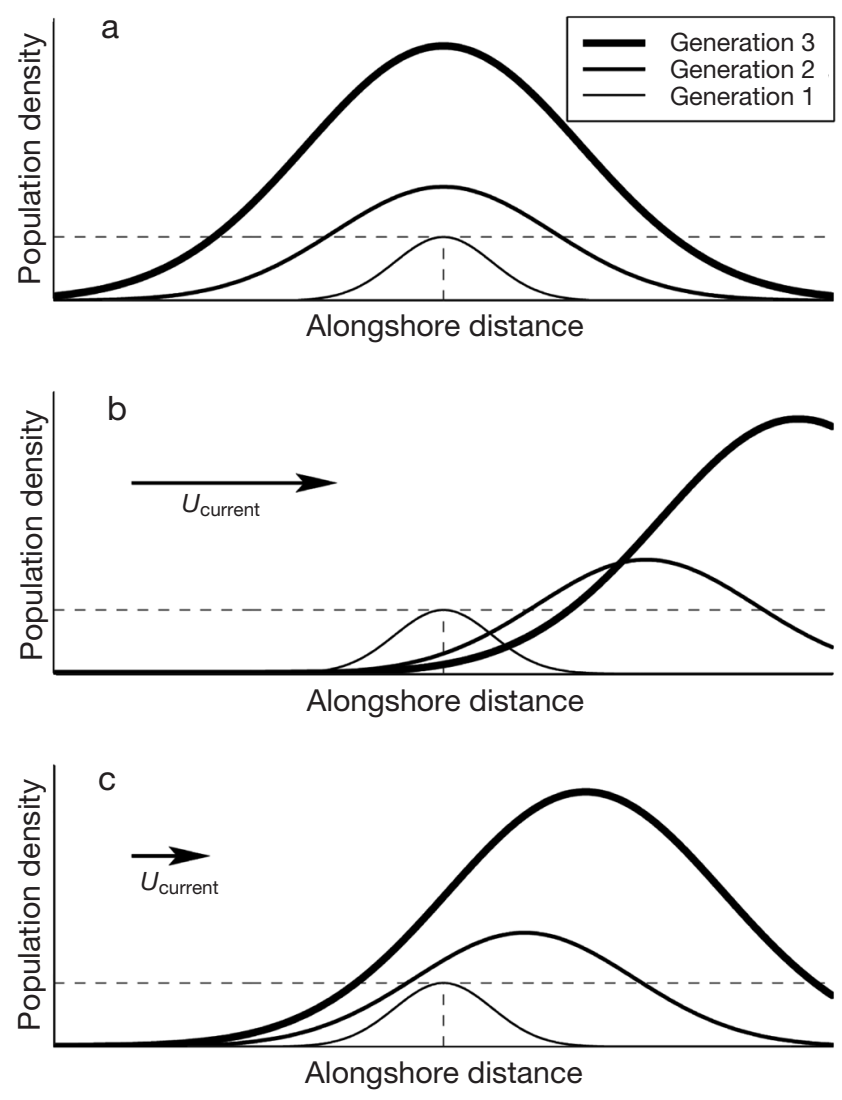

Fig. 1. Spread of a semelparous organism with a planktonic larval stage in an advective/diffusive environment. (a) Spread of the organism introduced in the middle of the domain (vertical dashed line) in an environment with no mean current. (b) Spread and downstream transport of an organism introduced at the same location, but in an ocean where $L_{\text {adv }}$ is large enough that Eq. (5) is not satisfied. The total population is still growing, but at the introduction site the population density is falling as the population is swept downstream. (c) Growth of the population in an ocean whose $L_{\text {adv }}$ is small enough that Eq. (5) is satisfied. The total population is increasing at the same rate as in the middle plot, but because $L_{\text {adv }}$ is less, fewer larvae are swept downstream and the population increases at the point of introduction and upstream. See Table 1 for parameter explanations

$$
\ln \left(N_{\text {fec }}\right)>\frac{L_{\text {adv }}^{2}}{2 L_{\text {diff }}^{2}}
$$

Thus the population will be retained if the mean transport of larvae $\left(L_{\mathrm{adv}}\right)$ is small, if the spread of the larvae $\left(L_{\text {diff }}\right)$ is large, or if the production of potentially successful larvae $N_{\text {fec }}$ is large (Fig. 2). This derivation is valid for any kernel where the location of the convergence of the population distribution to a Gaussian advances upstream by a distance greater than $L_{\mathrm{adv}}$ each generation. It will fail when the dispersal kernel has a finite upstream extent, so that no offspring are returned to the location of their parents. In a uniform domain, the ability to be retained and to invade 
upstream is linked. As can be seen in Figs. $1 \& 2$, when $N_{\text {fec }}$ is large enough to allow a species to be retained, the population grows not only where the species has been introduced, but upstream of that point as well, allowing the population to expand its range upstream. Pachepsky et al. (2005) relate this result to the invasion speed of Fisher (1937) and Skellam (1951).

The derivation above for Eq. (5) is only formally correct in an infinite domain, in the absence of density dependent growth, and for non-leptokurtic kernels. Lutscher et al. (2005) shows that Eq. (5) remains valid even if the success of larvae depends on the population density (cf. Kot et al. 1996). They also show that Eq. (5) is valid for finite domains much larger than $L_{\mathrm{adv}}$ and $L_{\text {diff, }}$ but for smaller domains $N_{\text {fec }}$ must be increased to allow retention. Lutscher et al. (2005) shows that for leptokurtic ('fat-tailed') kernels, a smaller $N_{\text {fec }}$ than predicted by Eq. (5) is needed to allow retention; however, observations and theory suggest that oceanic dispersal kernels for Lagrangian particles in the ocean are not leptokurtic (Davis 1985, Siegel et al. 2003).

\section{Iteroparous species}

The results derived above are for semelparous species, and must be modified for a species that lives and spawns over multiple generations. Unfortunately, the simple derivation above becomes significantly more complex for iteroparous organisms because of the need to account for the age structure of the population. To describe the impact of iteroparity, we analyze a simplified numerical model in which an adult reproduces for $N_{\text {gen }}$ generations, and then dies. In each generation, each adult releases $N_{\text {fec }}$ larvae which would recruit and survive to adulthood in the absence of density dependence. Thus the total maximum number of offspring an adult will leave in a lifetime in the absence of density dependence is $N_{\text {gen }} \times N_{\text {fec }}$ (the intrinsic capacity for increase over a lifetime). As above, the larvae released in each generation are dispersed on average a distance $L_{\mathrm{adv}}$ with a SD of $L_{\text {diff }}$ around that average. The numerical model incorporates a logistic density dependence. Further details of the numerical model are presented in Appendix 1.

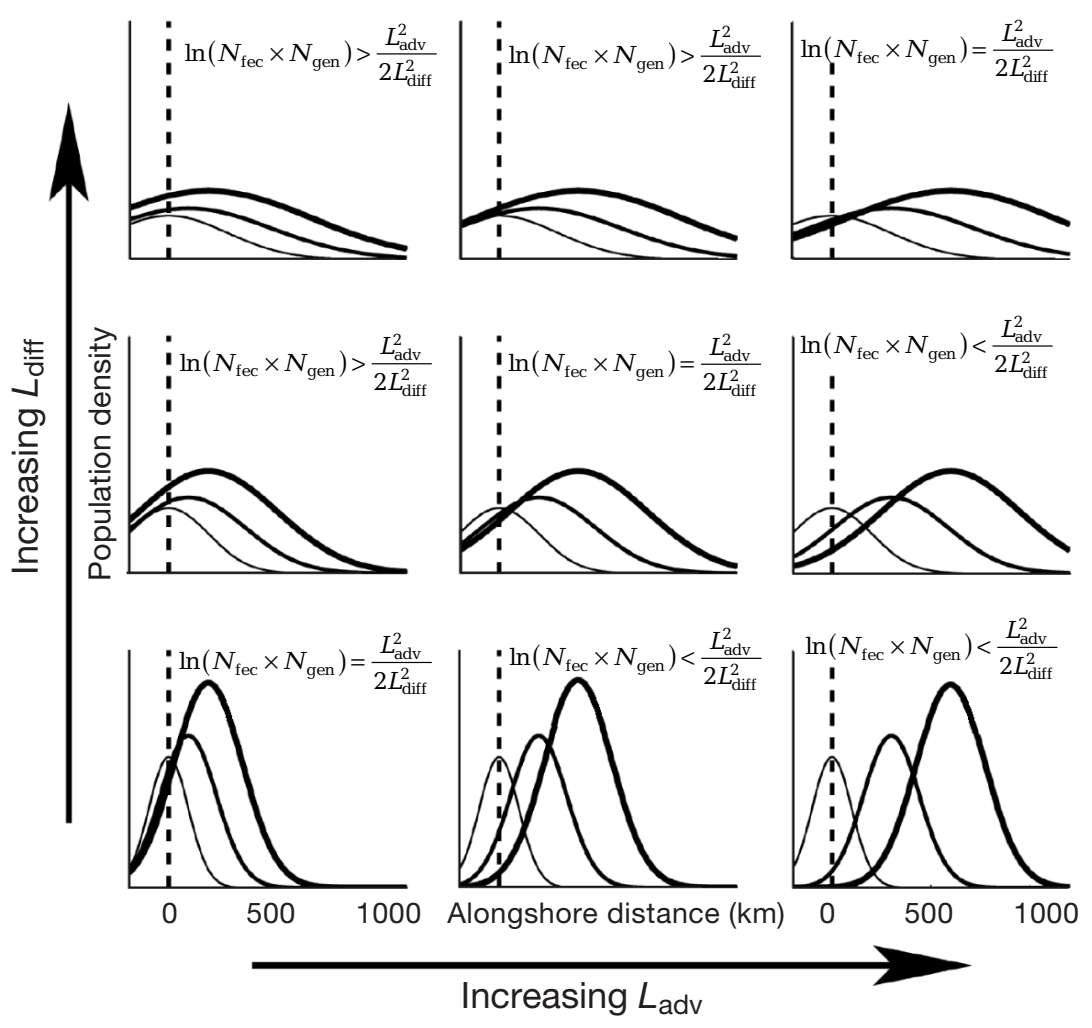

- generation $3-$ generation $2-$ generation 1

Fig. 2. Spread of a population introduced at $y=0$ (dashed line) for 3 generations. The current moves to the right, and $L_{\mathrm{adv}}$ and $L_{\text {diff }}$ are varied from 100 to $300 \mathrm{~km}$. increases. This growth rate is sufficient to allow retention at $y=0$ and upstream invasion in the upper left panels, where $L_{\text {diff }}$ is relatively large and $L_{\text {adv }}$ is relasmall and $L_{\text {adv }}$ relatively large, the population growth rate is insufficient to allow retention. Along the diagonal, where $L_{\mathrm{adv}}=L_{\mathrm{diff}}$, the growth rate is very nearly large enough to allow retention. See Table 1 for parameter explanations

An analytic solution to this non-linear model is complex. However, the number of parameters involved are small ( $L_{\mathrm{adv}}, L_{\text {diff, }} N_{\text {gen }}$, and $N_{\text {fec }}$ ), and dimensional analysis finds that any property of the system can be described by 2 non-dimensional parameters (Kundu 1990). The non-dimensional parameter $1 / 2 \times L_{\text {adv }}^{2} \times L_{\text {diff }}^{-2}$ was found to be useful in Eq. (5), so the other appropriate parameter must be $N_{\text {fec }} \times N_{\text {gen }}$. To determine how these 2 parameters control retention, the numerical model described above was initialized with a single individual in the center of the domain and was run until the population either filled the domain, or went extinct in the domain. The numerical model was then used to find the maximum value of $\exp \left(1 / 2 \times L_{\text {adv }}^{2} \times L_{\text {diff }}^{-2}\right)$ that allowed the population to be retained and to persist in the domain. This was done for a large number of permutations of $N_{\text {fec }}$ and $N_{\text {gen }}$ (Fig. 3), and it was found that the population is retained when: 


$$
\ln \left(N_{\text {fec }} N_{\text {gen }}\right)>\frac{L_{\text {adv }}^{2}}{2 L_{\text {diff }}^{2}}
$$

This is equivalent to Eq. (5) when $N_{\text {gen }}=1$ and the organism is semelparous.

$N_{\text {fec }} \times N_{\text {gen }}$ is simply the number of surviving offspring that a species would leave after a lifetime in an environment so sparsely populated that density dependence does not affect recruitment success. Additional numerical experiments confirm that when an organism has a different $N_{\text {fec }}$ for each age, retention is still controlled by the total number of offspring produced over a lifetime that would be successful in the absence of density dependence. Thus, longevity increases retention by allowing an individual to leave more offspring over its entire lifespan. The importance of lifetime surviving offspring as the crucial parameter contrasts with earlier results which did not explicitly include longevity, in which retention depended most on the instantaneous growth rate of the population (e.g. Speirs \& Gurney 2001, Pachepsky et al. 2005). Their criteria would overstate the growth rate needed to allow retention by a factor of $N_{\text {gen }}$. In the following sections, the impact of temporally variable $L_{\text {adv }}$ and $L_{\text {diff }}$ on retention are considered, and it is shown that iteroparity has a further benefit on retention.

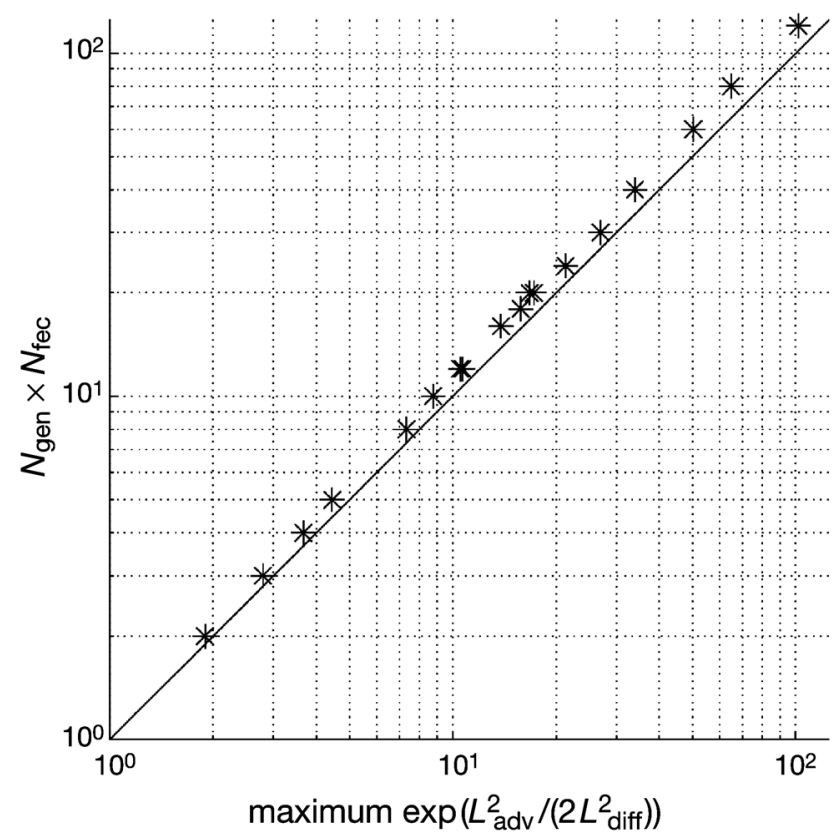

Fig. 3. For iteroparous and semelparous species the maximum value of $\exp \left[L_{\text {adv }}^{2} /\left(2 L_{\text {diff }}^{2}\right)\right]$ that allows retention in the numerical model ( $x$-axis) and $N_{\text {fec }} \times N_{\text {gen }}$ in the numerical model ( $y$-axis). Model runs were made for $N_{\text {fec }}=2,3,4,5,10$ and 20 larvae per adult per generation for adults that lived 1, 2, 4 and 6 generations. Solid line is the 1:1 line. Model results do not lie exactly along the line due to small numerical errors described in Appendix 1. See Table 1 for parameter explanations

\section{Physical oceanographic controls on retention}

By substituting the definitions of both $L_{\text {adv }}$ (Eq. 1) and $L_{\text {diff }}$ (Eq. 2) into the criterion for retention at a given site (Eq. 6), it is possible to see how larval planktonic duration and population growth interact with the mean currents and the strength and duration of the current variations to determine retention. Retention and invasion will occur when

$$
\ln \left(N_{\text {gen }} N_{\text {fec }}\right)>\frac{U_{\text {current }}^{2} T_{m}}{2 \sigma^{2} \tau_{\mathrm{L}}}
$$

Note that while $U_{\text {current, }} \sigma$ and $\tau_{\mathrm{L}}$ are physical parameters, they will be influenced by larval behavior (e.g. the depth of the larvae). The variables $N_{\text {fec }} \times N_{\text {gen }}$ and $T_{m}$ are determined solely by the biology of the species and interactions with water properties, e.g. temperature. Ultimately, more $N_{\text {fec }} \times N_{\text {gen }}$ and less $T_{m}$ are equivalent in their effects on population retention, so in an evolutionary sense, an individual can increase its ability to be retained by either increasing its fecundity or decreasing the time its larvae spend in the plankton (Fig. 4).

\section{Impacts of multiple spawning events within a generation}

For an individual to increase its ability to be retained at a given fecundity $N_{\text {fec }}$ and $T_{m}$ it must either reduce the mean advection of its larvae, or increase the variability of the advection experienced by larvae. It can do both by releasing its larvae during different seasons with different mean currents. We can quantitatively define how fluctuations in the mean current between spawning events will allow an iteroparous species to be retained with a lower level of fecundity. The simplest case to examine is when a species can spawn in 2 different seasons within a single generation. If the larvae from each spawning event live to the same time as part of a single cohort, and if (somewhat artificially) the offspring from the first spawn do not adversely affect the ability of the second spawning group to find available habitat, we can treat these 2 spawning events as a single event, with a composite $L_{\text {diff }}$ and $L_{\text {adv }}$. If the larvae are released in multiple seasons with different oceanographic conditions, then $L_{\text {adv }}$ is the mean distance from the mother to the settling location of all of the larvae released in a generation, and $L_{\text {diff }}$ is the SD of the recruitment locations of all those larvae. Let us assume that the larvae from each spawning event are dispersed with a Gaussian kernel. For 2 spawning events in different seasons, the first of which releases $C_{1}$ larvae that successfully recruit $L_{\mathrm{adv} 1} \pm L_{\mathrm{diff} 1}$ down- 
stream, and the second of which releases $C_{2}$ larvae that successfully recruit $L_{\text {adv2 }} \pm L_{\text {diff2 }}$ downstream (so that $C_{1}+C_{2}=N_{\text {fec }}$ ), the resulting larval dispersal parameters are:

$$
\begin{aligned}
& L_{\mathrm{adv}}=\frac{C_{1} L_{\mathrm{adv} 1}+C_{2} L_{\mathrm{adv} 2}}{C_{1}+C_{2}} \\
& L_{\mathrm{diff}}=\sqrt{\frac{C_{1}}{C_{1}+C_{2}}\left[\left(L_{\mathrm{diff} 1}^{2}+\left(L_{\mathrm{adv} 1}-L_{\mathrm{adv}}\right)^{2}\right)\right]+} \\
& \frac{C_{2}}{C_{1}+C_{2}}\left[\left(L_{\mathrm{diff} 2}^{2}+\left(L_{\mathrm{adv} 2}-L_{\mathrm{adv}}\right)^{2}\right)\right]
\end{aligned}
$$

from the direct computation of the variance and mean of 2 Gaussian kernels. These composite $L_{\text {diff }}$ and $L_{\text {adv }}$ can be used in Eq. (6) to judge if a species is retained.

In order to understand the impact of multiple spawning events on retention, it is instructive to consider the case in which the dispersal and the fraction of larvae released that are successful are equal between spawning $\left(L_{\text {diff1 }}=L_{\text {diff2 }}\right.$ and $\left.C_{1}=C_{2}\right)$. In this case,

and

$$
L_{\mathrm{adv}}=\frac{1}{2}\left(L_{\mathrm{adv} 1}+L_{\mathrm{adv} 2}\right)
$$

$$
L_{\text {diff }}=\left(L_{\text {diff }}^{2}+\frac{1}{4}\left(L_{\mathrm{adv} 1}-L_{\mathrm{adv} 2}\right)^{2}\right)^{\frac{1}{2}}
$$

From this we can see that retention is made easier by a second spawning event if the second spawn is transported a lesser distance or in an opposite direction than the first spawn both because the composite $L_{\text {adv }}$ is decreased, and be-

cause the composite $L_{\text {diff }}$ is increased. Thus, multiple spawning events will enhance retention if they increase the variability of the currents larvae encounter, and reduce the mean distance the larvae move.

\section{Longevity and multiple spawning events across generations}

In the prior section it was shown that multiple spawning events in a single year could enhance retention by increasing the SD of the larval dispersal distance $L_{\text {diff. }}$. If an organism lives for multiple years, interannual variation in the currents would similarly tend to increase its ability to be retained by the mean currents.

However, the discussion in the previous section is not formally applicable to iteroparous species that spawn in separate years, for that derivation did not for-
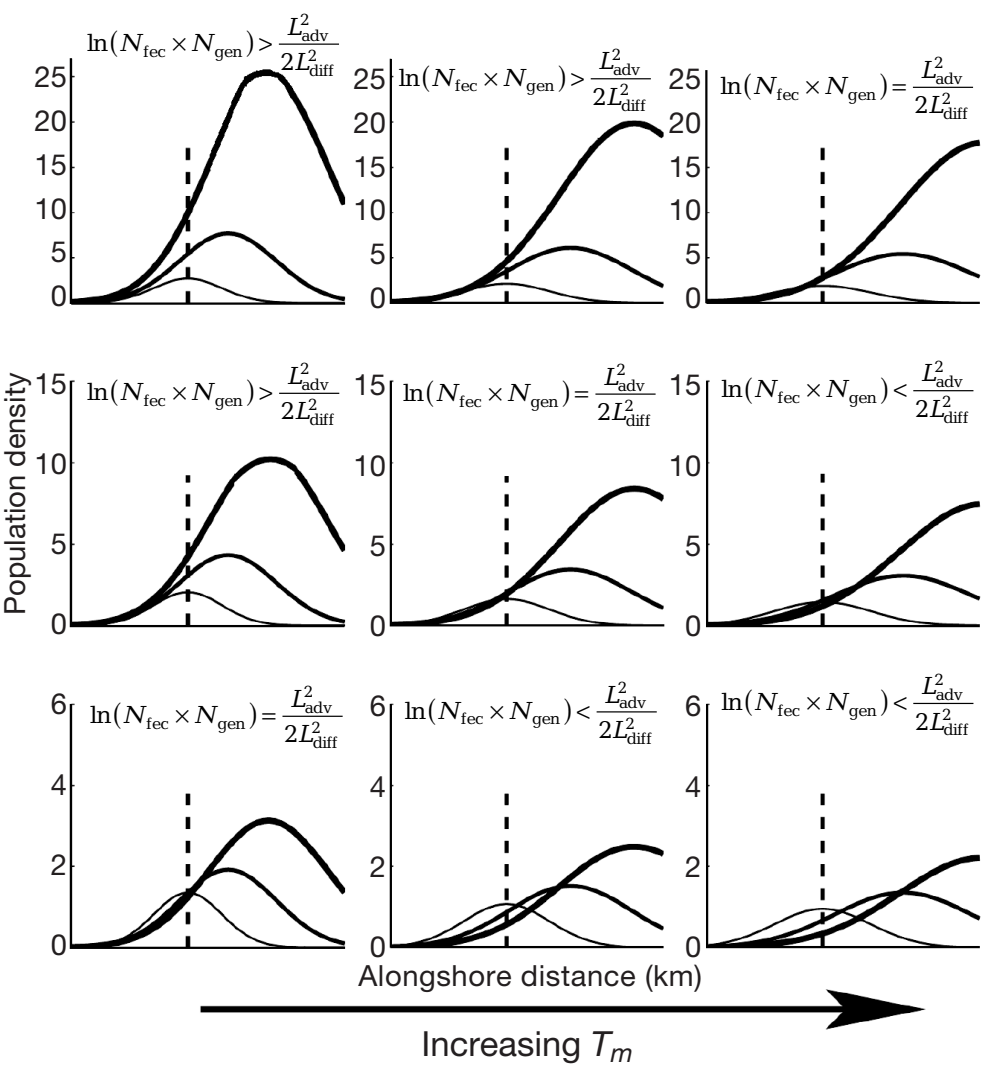

generation $3-$ generation $2-$ generation 1

Fig. 4. Spread of a population introduced at $y=0$ (dashed line) over 3 generations for a variety of growth and larval planktonic durations. The current increases from 2 to 4 per generation in the vertical. $T_{m}$ was chosen so that $\ln \left(N_{\text {fec }} \times N_{\text {gen }}\right)=\left(U_{\text {current }}^{2} T_{m}\right) /\left(2 \sigma^{2} \tau_{\mathrm{L}}\right)$ along the diagonal, 等 right, where $N_{\text {fec }}$ is small and $T_{m}$ large (Eq. 7). As $T_{m}$ increases across the curves, larvae spend more time on average exposed to the mean advection and are spread farther downstream. See Table 1 for parameter explanations

mally account for changes in population level and distribution between spawning events. Nevertheless, it is reasonable to apply Eq. (9) to the case of inter-annually varying mean flows, and to use the numerical model described in the appendix to judge its accuracy. In order to simplify the discussion, $L_{\text {diff }}$ will be kept constant between years.

Eq. (9) is written for just 2 spawning events. To include the case in which $L_{\mathrm{adv}}$ varies between several years, we note that Eq. (9) is the quadratic mean of $L_{\text {diff }}$ and the square root of the sample variance of $L_{\mathrm{adv}}$, defined as:

$$
\frac{1}{N_{\text {gen }}} \sum_{i=1}^{N_{\text {gen }}}\left(L_{\mathrm{adv}_{i}}-\overline{L_{\text {adv }}}\right)^{2}
$$

where $\overline{L_{\mathrm{adv}}}$ is the mean value of $L_{\mathrm{adv}}$ calculated over the lifetime of a single individual. This estimate of the variance of $L_{\mathrm{adv}}$ is biased (Roberts \& Riccardo 1999) from 
the true variance of $L_{\mathrm{adv}}$ by a factor of $\left(1-N_{\mathrm{gen}}^{-1}\right)$. Thus Eq. (9) can be extended to include interannual variability of $L_{\mathrm{adv}}$ by writing it as:

$$
L_{\text {diffeffect }}=\left(L_{\text {diff }}^{2}+\left(1-N_{\text {gen }}^{-1}\right) \sigma_{L_{\text {adv }}^{2}}^{2}\right)^{\frac{1}{2}}
$$

where $\sigma_{L_{\mathrm{adv}}}$ is the true interannual variance of $L_{\mathrm{adv}} . L_{\mathrm{diff}}$ is the SD of larval dispersal within a single year or spawning event, whereas $L_{\text {diffeffect }}$ is the SD of larval dispersal distance for all larvae released over the lifetime of an adult. The variable $\sigma_{L_{\mathrm{adv}}}$ differs from $\sigma$ used in Eq. (2) in that $\sigma$ is the SD of the instantaneous currents experienced by larvae from a single spawning event, while $\sigma_{L_{\mathrm{adv}}}$ is the SD of the mean distance moved by larvae from different spawning events. In order to test if Eq. (11) can be used to determine the retention of a species, we ran the numerical model described in Appendix 1, changing $L_{\mathrm{adv}}$ for the entire domain each generation, and allowing this variable $L_{\text {adv }}$ to have a $\mathrm{SD}$ of $\sigma_{L_{\mathrm{adv}}}$. The model was then run with many different values of $\sigma_{L_{\mathrm{adv}}}$ and for each, the minimum value of $N_{\text {fec }}$ was found which allows retention. In Fig. 5, the results of these model runs are shown and compared to Eq. (6) as calculated with the interannual mean $L_{\mathrm{adv}}$ and $L_{\text {diffeffect }}$ from Eq. (11) in place of $L_{\text {diff. The change }}$ in the minimum $N_{\text {fec }}$ needed to allow retention is consistent with the predictions of Eqs. (6) \& (11), showing

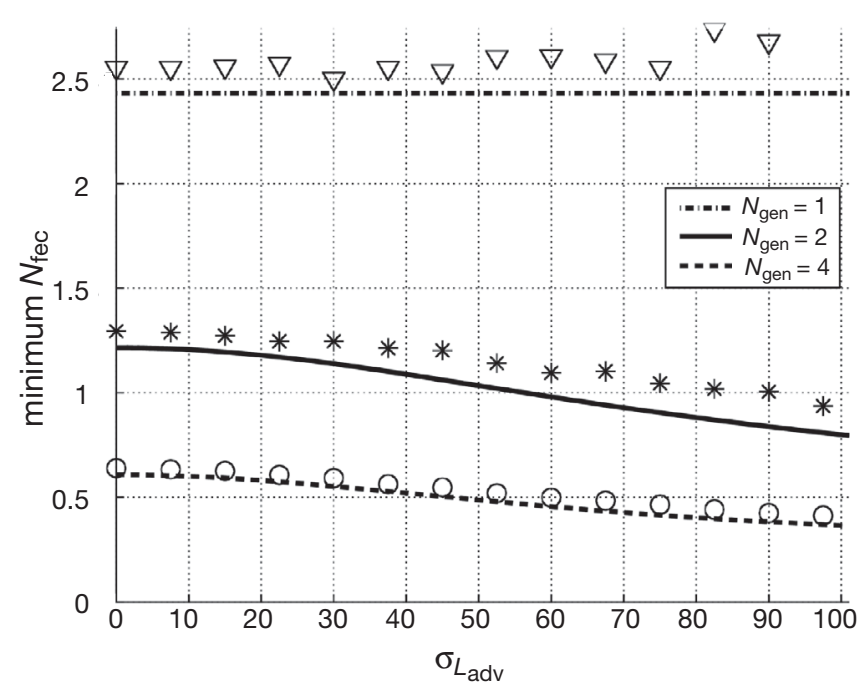

Fig. 5. Minimum value of $N_{\text {fec }}$ required to allow retention as a function of the interannual variability of the mean larval transport, $\sigma_{L_{\mathrm{adv}}}$. Mean value of $L_{\mathrm{adv}}$ is $100 \mathrm{~km}$, and $L_{\text {diff }}$ is $75 \mathrm{~km}$. Lines are from Eq. (6) calculated using an effective diffusivity from Eq. (11), and the individual points are from the numerical model described in Appendix 1. Curves are shown for organisms which live for 1,2 and 4 generations. The numerical model growth minimum values of $N_{\text {fec }}$ were slightly larger than expected from theory due to approximations made in the numerical model and discussed in Appendix 1. See Table 1 for parameter explanations that they capture the effects of interannual variation in the mean flow on the retention of a species. Thus year to year variability in the mean currents can significantly aid in the retention of organisms that spawn for multiple years by increasing variability in the dispersal of larvae.

\section{DISCUSSION}

The results presented here illustrate the importance of variability in the currents of the ocean to the retention of a species and its ability to spread upstream. However, a single value, for example for eddy diffusion (e.g. Speirs \& Gurney 2001 or Pachepsky et al. 2005) or the $\sigma$ of Eqs. (2) \& (7), will not capture the impact of flow variability on all species. The variability in the dispersal of the larvae that allows retention depends sensitively on the life history of the organism. If the species is semelparous, a single eddy diffusivity or a single number describing the strength of the current fluctuations during the release of a larvae can describe the random component of larval dispersal. But if an organism spawns in 2 seasons, it is necessary to include both effect of the variability in the currents experienced by the larvae in each spawning event, and the variation in the mean currents between spawning events (Eq. 9). If an organism lives for multiple years, the interannual variability of the mean distance the larvae are moved each year, $\sigma_{L_{\mathrm{adv}}}$ becomes important as well (Eq. 11). What matters in all of these cases is the spatial spread of the larvae released by a single organism over its entire lifetime, and in most cases it will be advantageous for retention (all other things being equal) to release larvae at multiple times into different currents.

In the following section we discuss how the majority of larval release times for benthic organisms with planktonic larvae in the North East Pacific are consistent with a strategy to enhance retention by taking advantage of oceanic variability, suggesting that enhancing retention is an important life history goal. This is followed by a discussion of larval retention and vertical behavior; the evolutionary tradeoffs between retention, fecundity, and the time in plankton; and the ecological implications of retention on species range limits and how these might change with a changing climate.

\section{Larval release timing in the northeast Pacific: optimized for retention?}

Reitzel et al. (2004) compiled data from Strathmann (1987) on larval release times of 142 species in the northeast Pacific. They found that brooding species 
release progeny evenly over the whole year, but for the 89 benthic species with planktonic larvae, $62 \%$ release larvae in April (Fig. 6). Both lecithotrophic and planktotrophic larvae peaked in this same period. These patterns held even for phylogenetically controlled comparisons. Thus, the confluence of many planktonproducing species (but not brooding species) across many phyla on this single reproductive peak suggests strong selective force(s) at work on the timing of larval release into the plankton.

Because lecithotrophic larvae are provisioned with food, it seems unlikely that food supply (e.g. the spring phytoplankton bloom) can fully explain the spring peak in larval release. Parental food supply also seems unlikely to explain this pattern since brooding species do not share a similar spawning peak in spring. Reitzel et al. (2004) invoked 2 primary explanations based on temperature. Both essentially revolve around the fact
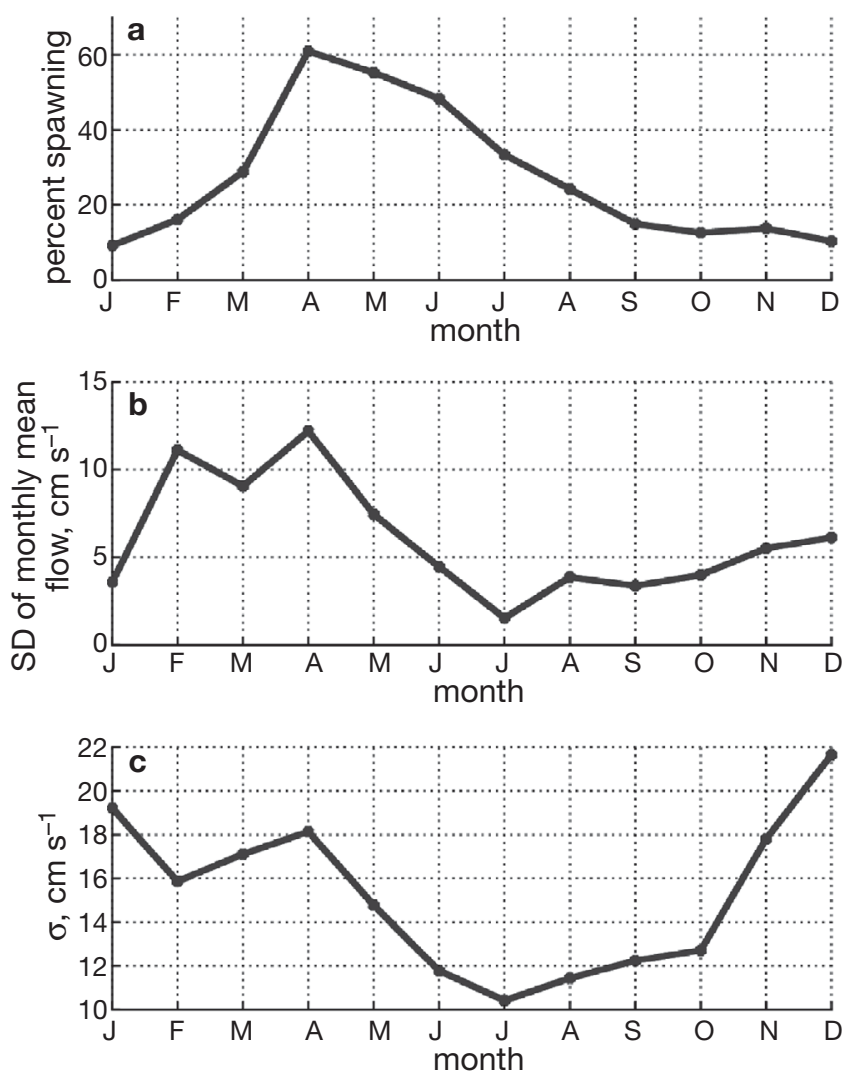

Fig. 6. (a) Fraction of northeast Pacific benthic species with planktonic larvae releasing larvae in each month (from Table 1 in Reitzel et al. [2004]). Included are 89 benthic species from 12 phyla. (b) SD of the monthly mean alongshore flow at $35 \mathrm{~m}$ from 10 years of data on the mid-shelf near Coos Bay, Oregon. Variability in the monthly mean flows will directly lead to variability in the mean transport of larvae each year, increasing $\sigma_{L_{\mathrm{adv}}}$ (c) Mean SD of the detrended along-shore velocity from the same mid-shelf location. See Table 1 for parameter explanations that because larvae typically develop faster in warmer water, the spring release may be an adaptation to reduce development time. However, because the greatest proportion of species spawn in April, not the time of peak water temperatures in the NE Pacific Ocean, Reitzel et al. (2004) had to invoke secondary assumptions to explain the discrepancy. We believe adaptation for retention may more parsimoniously explain the peak in spring spawning. Although faster development time would decrease $T_{m}$ and thus aid retention, a more important factor may be the current patterns themselves.

Retention of larvae released in a single month will be optimized if larvae are released in the month when mean currents are minimal, when variability in currents is maximal, and, for iteroparous organisms, when there is the largest interannual variability in the mean currents. In the northeast Pacific these conditions converge in April. Many studies have found that upper water column, mid-shelf currents from Northern California to the Canadian border change from mean poleward to equatorward flow in March/April, and back to poleward flow in late-summer (Strub et al. 1987, Huyer et al. 1979, Lentz 1987). There are fewer current observations that are long enough to evaluate interannual variability; however, in $10 \mathrm{yr}$ of data from the $95 \mathrm{~m}$ isobath near Coos Bay, Oregon $\left(43.15^{\circ} \mathrm{N}, 124.56^{\circ} \mathrm{W}\right)$ (1981 to 1991 data courtesy of OSU Bouy group and 2001 to 2004 from Barbara Hickey/GLOBEC), the intra-seasonal current variability $\sigma$ (which leads to $L_{\text {diff }}$ ), is large all winter and begins to decline sharply in May to reach a minimum in July. Furthermore, the inter-annual variability in the monthly mean alongshore currents, and thus $\sigma_{\text {Ladv }}$ is greatest in April, somewhat weaker in winter, and weakest in summer (Fig. 6).

Thus, the month that Reitzel et al. (2004) found $62 \%$ of species releasing larvae, April, is a good time for the retention of species with planktonic larvae because mean currents $\left(L_{\text {adv }}\right)$ around this time reverse and the inter-annual and intra-seasonal variability of currents $\left(\sigma_{L_{\mathrm{adv}}}\right.$ and $\sigma$, respectively) are large. Furthermore, an additional $13 \%$ of species with planktonic larvae release them in multiple months in which the alongshore currents are flowing in opposite directions (currents from Strub et al. [1987] Fig. 8, midshelf at $43^{\circ} \mathrm{N}$ ). This larval release pattern would also tend to enhance retention by spreading larvae both up and down the coast. Thus $75 \%$ of species are found to release their larvae in the month in which the alongshelf currents are very favorable for retention (April), or in multiple months in which the mean alongshore currents disperse larvae both up and down the coast, or both. We thus believe the most parsimonious explanation may be that the larvae are being released to 
maximize retention, and that the observed pattern strongly supports the importance of adapting larval release to increase retention.

\section{Adaptations to allow invasion and retention at lower growth rates: effects of larval depth}

In the bulk of the analysis presented here, retention is described as a function of the circulation, the timing of spawning, and the fecundity of the species. However, individuals can also reduce the ratio $L_{\mathrm{adv}} / L_{\mathrm{diff}}$, and thus the propagule production $\left(N_{\text {fec }} \times N_{\text {gen }}\right)$ needed to allow retention and encourage invasion, through larval behavior. Here we examine one possibility - the vertical positioning behavior of larvae. Larvae deeper in the water column often (but not always) experience weaker currents (e.g. in Central California: Winant et al. [1987]; in the Mid-Atlantic Bight: Beardsley et al. [1985]). However, these weaker currents do not themselves aid upstream retention since to reduce the growth rate needed to allow retention, the ratio of the mean current $\left(U_{\text {current }}\right)$ to its fluctuations $(\sigma)$ must be reduced (Eq. 7). It is only advantageous for an individual trying to have its larvae retained to stay deep in the water column if the mean flow is reduced with depth while the fluctuations in the flow are not, since it is the relative strength of fluctuations that determines upstream retention and invasion. These conditions do occur in some oceans. Shearman \& Lentz (2003) analyzed the flow south of Cape Cod in the approaches to the Mid-Atlantic Bight and found that the mean currents decreased approximately linearly towards the bottom, while the strength of the fluctuating currents was relatively independent of depth outside of the surface and bottom boundary layers. Thus in this ocean, the ratio of $U_{\text {current }}$ to the fluctuating component of the currents, $\sigma$, decreases with depth (Fig. 7). A larva residing deeper in this ocean would be more easily retained, and would invade upstream more easily, all else being equal.

\section{Evolutionary trade-offs between fecundity, planktonic duration, iteroparity, and retention}

As can be seen in Eqs. (1) \& (2), the mean distance moved by larvae $L_{\text {adv }}$ increases linearly with time, but the $\mathrm{SD}$ of the distance $L_{\text {diff }}$ only increases as the square root of time because the effects of random motions will tend to average out with time. Thus, as seen in Eq. (7), a longer time in plankton reduces the likelihood that a semelparous species will be retained. The longer the larvae are in the plankton, the more likely it is that the sum of the random transport by fluctuat-

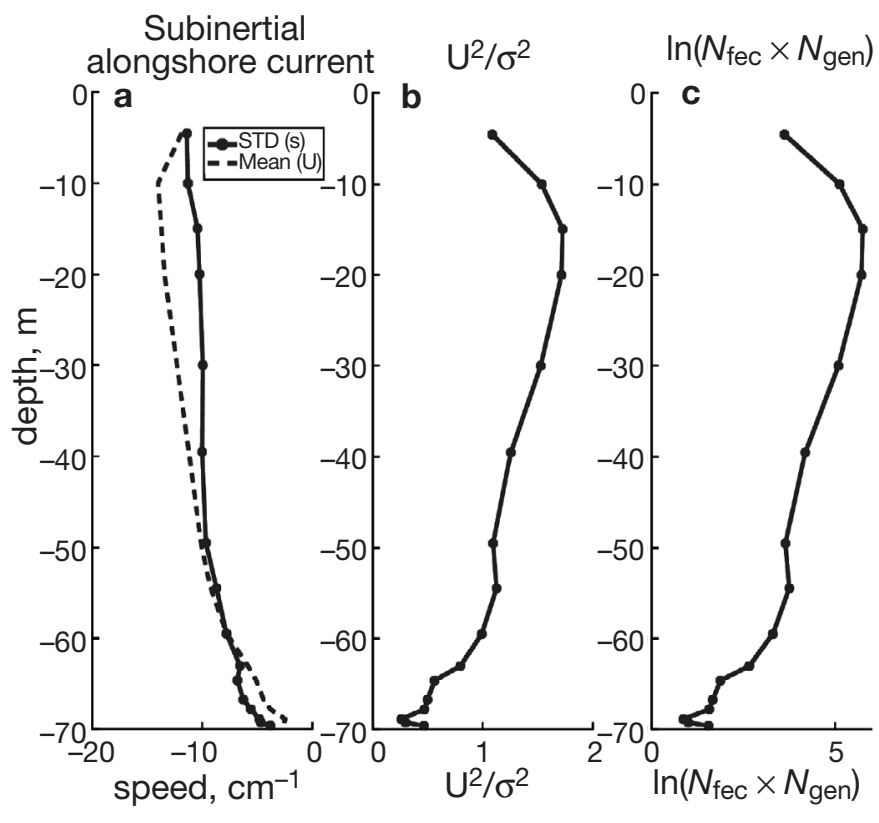

Fig. 7. (a) Mean ( $\left.U_{\text {current }}\right)$ and negative of the SD $(\sigma)$ of inertial alongshore currents on the $70 \mathrm{~m}$ isobath south of Cape Cod for the fall of 1996 (Shearman \& Lentz 2003). A negative current is towards the west. (b) Square of the ratio of the mean to fluctuating sub-inertial Eulerian currents $\left(\mathrm{U}^{2} / \sigma^{2}\right)$ on the $70 \mathrm{~m}$ isobath. The amount of growth needed for a population to be retained in its habitat along this coast scales as $\left(\mathrm{U}^{2} / \sigma^{2}\right)$, and at this location would reach a minimum near the bottom. (c) Logarithm of the recruit production, $N_{\text {fec }} \times N_{\text {gen }}$, as a function of depth, that would be needed to retain the population of an organism with a larval duration of $2 \mathrm{wk}$ in the presence of this mean current (Eq. 7). This growth rate is smallest near the bottom with a secondary minimum near the surface where the mean wind-driven Ekman flows particular to this location tend to reduce the mean alongshore surface currents. Data are from Coastal Mixing and Optics experiment, courtesy of R. K. Shearman and S. J. Lentz (Shearman \& Lentz 2003). See Table 1 for parameter explanations

ing currents will be less than the transport by the mean current (Fig. 4). Thus a larva can defy the odds of being transported downstream in the mean current and move upstream by fortuitously catching a fluctuating current over a short time. However, its luck will run out if it stays in the plankton too long, since the odds ultimately favor movement in the predominant downstream direction. In the face of this result, why do organisms produce larvae which spend a long time in the plankton? Two possibilities are given below. The first is that reproductive output and planktonic duration are, in an evolutionary sense, correlated. The second is that for iteroparous species, increased time in plankton can have less of an impact on retention than for a semelparous species due to the interannual variation of the currents.

Reductions in $T_{m}$ over evolutionary time are unlikely to be achieved independently of $N_{\text {fec }}$. This is because highly fecund adults typically produce many relatively 
unprovisioned larvae that require a longer time in the plankton to feed and develop before achieving competency to settle and assume a benthic lifestyle (e.g. Thorson 1950, Vance 1973, Strathmann 1980, 1990, Pechenik 1999). Thus reducing $T_{m}$ necessitates more investment in each offspring, limiting the total number of young that can be produced by a mother. Since lowering $T_{m}$ and raising $N_{\text {fec }}$ have identical effects on upstream retention, evolutionarily which strategy should prevail? From the perspective of upstream retention, the answer depends on whether $N_{\text {fec }}$ increases fast enough to offset the coupled increase in $T_{m}$. If the logarithm of the production of larvae that can successfully recruit, $\ln \left(N_{\text {fec }}\right)$, increases faster than the time spent in the plankton, it is advantageous for a species to increase $T_{m}$ in order to increase $N_{\text {fec }}$ (Eq. 7, Fig. 4). Strategies that decrease $T_{m}$ without affecting $N_{\text {fec }}$ should be heavily favored. For example, because larvae usually develop faster in warmer water, all else being equal, summer spawning could be due in part to selection to minimize $T_{m}$ without otherwise reducing $N_{\text {fec }}$.

For iteroparous species, the impact of a larger time in plankton $T_{m}$ may be less than suggested by Eq. (7). Eq. (11) states that the SD of the distance dispersed by all the larvae an iteroparous adult releases over its lifetime, $L_{\text {diffeffect, }}$ depends in part on the SD of $L_{\text {adv }}$ from year to year, $\sigma_{L_{\mathrm{adv}}}$. Because $L_{\mathrm{adv}}$ for each year scales linearly with $T_{m}, \sigma_{L_{\text {adv }}}$ will scale linearly with $T_{m}$ to the extent that the timescale of the interannual variations in currents is longer than $T_{m}$. As can be seen from Eq. (11), as $\sigma_{L_{\mathrm{adv}}}$ increases, it grows to dominate $L_{\text {diffeffect, }}$ and so when $T_{m}$ grows large enough, $L_{\text {diffeffect }}$ will tend to scale linearly with $T_{m}$. In this limit, the fecundity needed to allow retention (from Eq. 7) will only increase slowly as $T_{m}$ increases. Thus while there is always an advantage to a reduced $T_{m}$, it may be slight for iteroparous species if interannual variability of the currents is high.

\section{Ecological implications and species range limits}

The edge of a species' distribution is often considered an area where the environment has become uninhabitable, and thus the population at the edge is unable to grow (see reviews by Caughley et al. 1988, Brown \& Lomolino 1998, Gaston 2003). The model above shows that in advective environments this is not necessarily true; the upstream edge of the species range limit can also occur where the species is able to successfully reproduce, but the reproduction is insufficient to balance the downstream loss of larvae due to the mean currents. If a population at the upstream edge of a domain has reproductive rate $N_{\text {fec }}$ that does not satisfy Eqs. (5) or (6), the population there will dwindle rapidly, and that portion of the domain will become uninhabited. Thus regions that would be habitable in the absence of a mean current may be unoccupied (Gaylord \& Gaines 2000, Gaines et al. 2003, Largier 2003). The species range boundary will then occur farther downstream, where growth is just sufficient to balance advection, and Eqs. (5) or (6) are satisfied. This is illustrated in Fig. 8, in which $L_{\text {adv }}$ is doubled in the upstream fifth of the domain, preventing Eq. (5) from being satisfied there. The population only becomes finite in the downstream portion of the domain, where the advection speed is slower. Prodigious output of dispersive propagules may have evolved in part to ensure that enough larvae survive and are moved upstream by variations in currents to replenish upstream populations. Ironically, this result suggests that long dispersal downstream could largely be a byproduct of copious larval production by species trying to stay in place in an advective environment.

It may seem un-intuitive that a theory built around the potentially successful larvae $\left(N_{\text {fec }}\right)$ in the absence of density dependence will be useful in determining the

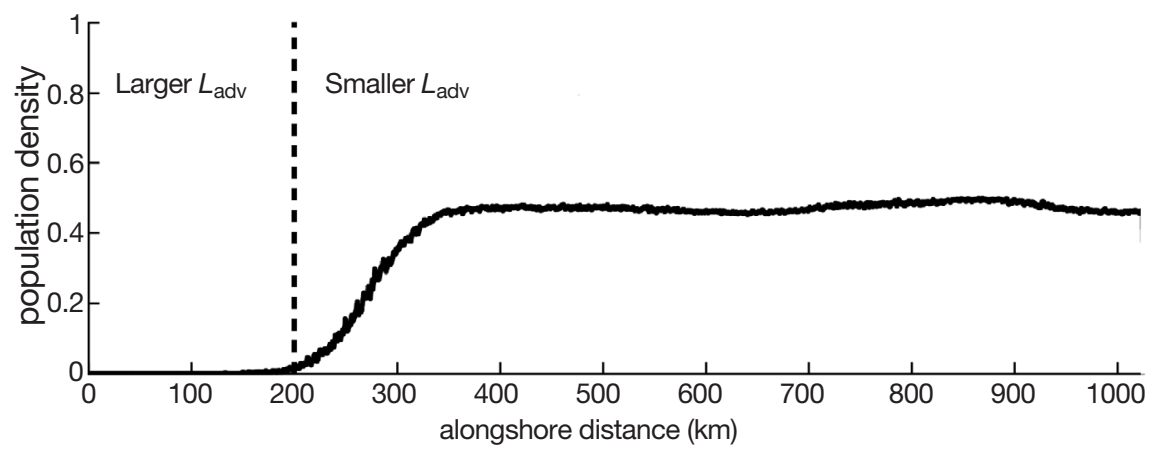

Fig. 8. Population density in a domain of $1000 \mathrm{~km}$ in which the mean currents vary in strength along the domain. The mean current flows to the right. $L_{\text {adv }}$ is $50 \%$ above the threshold for retention to the left of the dashed line, and is $50 \%$ below the threshold to the right of the dashed line. The population can only be retained to the right of the line, and so there is nearly no population to the left of the line. The very small population to the left consists of the occasional larvae which arrive left of the line, but are unable to establish a population that persists because too many of their offspring are washed downstream 
range limit in a species whose population has reached steady state. However, when the population is at the threshold of not being retained, where Eqs. (5) and (6) are only just satisfied, the population density will become small enough at the upstream edge that density dependent effects no longer matter (Fig. 8).

If range boundaries are set by strong advection, one way a species with a flexible life history could retain populations on the edge, and thus extend its range upstream of where it might not otherwise be able to maintain its population, is by reducing $T_{m}$ to near zero at the upstream edge and thus more easily satisfying Eqs. (6) \& (7). Such a strategy may help to explain why many species with mixed modes of reproduction (e.g. vegetative or sexual reproduction) primarily reproduce vegetatively or asexually at their distributional limits (Dixon 1965, Whittick 1978, De Wreede \& Klinger 1988, Eckert 2002, Billingham et al. 2003). A preponderance of marine algae and angiosperms use vegetative propagation as the principal means of reproduction at extremes of their distributions and in areas with strong advection (De Wreede \& Klinger 1988).

Any environmentally induced changes in larval parameters can also limit or alter a species' range by changing its ability to be retained. Most notably, the larvae of many species develop more slowly as temperature decreases (e.g. Pearse et al. 1991, Clarke 1992). As the obligate time in plankton $T_{m}$ increases, the growth a population needs to retain and spread upstream increases (Eq. 7). On the northeast coast of North America, the mean flow is southwestward, the mean temperature increases to the southwest, and so the upstream northern edge of a species' range could be limited to the point where $N_{\text {fec }}$ is not large enough to compensate for the increase in $T_{m}$ in colder waters to allow retention. This may also limit the northward spread of some invasive species. For example, the obligate minimum time in plankton for the Asian crab Hemigrapsus sanguineus measured in lab experiments increased from $16 \mathrm{~d}$ at $25^{\circ} \mathrm{C}$ to $21 \mathrm{~d}$ at $20^{\circ} \mathrm{C}$ to $53 \mathrm{~d}$ at $15^{\circ} \mathrm{C}$, for oceanic salinities (Epifanio et al. 1998). The mean near-shore shelf flows along much of the northeastern coast of North America (i.e. the Mid-Atlantic Bight, Gulf of Maine, and Scotian Shelf) are about $9 \mathrm{~cm}$ $\mathrm{s}^{-1}$ (Beardsley et al. 1985, Pettigrew et al. 1998, Smith et al. 2001, Hetland \& Signell 2005), the strength of the sub-inertial alongshore current fluctuations $(\sigma)$ in the summer are roughly $9 \mathrm{~cm} \mathrm{~s}^{-1}$, and the Lagrangian decorrelation timescales of the east/west currents $\left(\tau_{\mathrm{L}}\right)$ is about $2 \mathrm{~d}$ (Brink et al. 2003, Beardsley et al. 1985).

The number of potentially successful larvae Hemigrapsus sanguineus must produce to allow retention is, from Eq. (7), $N_{\text {fec }} \times N_{\text {gen }}=50$ for $25^{\circ} \mathrm{C}$ water, or about $0.02 \%$ net larval survival in a single year based on an upper estimate of per capita fecundity of 200000 to 300000 eggs $\mathrm{yr}^{-1}$ (McDermott 1991). For $20^{\circ} \mathrm{C}, N_{\mathrm{fec}} \times$ $N_{\text {gen }}=200$, or $0.08 \%$ survival. These temperatures thus produce net larval recruitment rates that are easily achieved given laboratory-based mortality rates for $H$. sanguineus (Epifanio et al. 1998), and decapod crustacean larvae in general (Morgan 1995). However, for $15^{\circ} \mathrm{C}, N_{\text {fec }} \times N_{\text {gen }}=568000$, which even at $100 \%$ survival exceeds the total number of larvae a female is expected to release in $2 \mathrm{yr}$. (These values of $N_{\text {fec }} \times N_{\text {gen }}$ are much larger than the values of $R$ typically observed in situ, which are usually between 1 and 10. However, in situ estimates of $R$ often include density dependent effects and neglect advection.)

These calculations suggest how Hemigrapsus sanguineus has been able to expand rapidly hundreds of kilometres upstream from its initial discovery in 1988 in Cape May, New Jersey (McDermott 1991), where summer surface water temperatures are roughly $20^{\circ} \mathrm{C}$ (Loder et al. 1998). But they also suggest that populations of $H$. sanguineus observed near the central coast of Maine (R. Seeley pers. comm.) where summer water temperatures are $\sim 15^{\circ} \mathrm{C}$ should be ephemeral. We caution that all of these estimates are hedged by great uncertainty, including the questionable applicability of laboratory based estimates of larval duration and mortality. However, the increase in the minimum intrinsic growth needed for retention as temperatures fall is so great that it suggests that the $H$. sanguineus invasion is near its northern limit in central Maine, and that limit is set by the decrease in temperature it experiences as it expands its range northward and the mean currents moving against the direction of its invasion. This conclusion would be invalidated if the population on the open shores is maintained by populations retained in estuaries where the mean alongshore current is small, or if the interannual variability in the currents is large enough that there are sufficient years when the transport of the larvae is northeastward and thus against the climatological average current (cf. Eq. 11). The former seems unlikely, for $H$. sanguineus larvae are observed to fail to develop at low estuarine salinities (Epifanio et al. 1998). However, we do not have sufficiently long time series of alongshore coastal currents in the Gulf of Maine to rule out the latter scenario, and will not until ocean observing systems in this area have been able to measure current variability for several more years.

More generally, decreased larval development times in warmer water implies that any increase in mean ocean temperatures due to global warming could allow equatorward species to extend their range poleward even against mean currents. Even small increases in annual mean temp $\left(0.5^{\circ} \mathrm{C}\right)$ can dramatically influence species distributions (Southward et al. 1995). These 
temperatures changes are usually suggested to alter a species' distribution by directly affecting adult and larval tolerances to temperature extremes (e.g. Southward et al. 1995). In contrast, our model suggests that upstream range expansion could occur in some oceans simply because an increase in water temperature decreases development time $\left(T_{m}\right)$ which facilitates retention and expansion upstream. Therefore global climate change may not need to change temperature enough to kill larvae and adults to change a species range; its influence on their development time may be enough to alter species ranges substantially.

\section{CONCLUSION}

In summary, currents can benefit spawning marine species by spreading larvae (often over large distances) with little energetic cost to the organism itself. Superficially that is often the extent of our perception of currents' influence on larval spread-that it is an energetically efficient dispersal mechanism. However, these same currents present a very real challenge to an organism, for it must avoid having too many of its larvae swept downstream, and thus being unable to persist in a region. For an organism (and its progeny) to be retained and to spread upstream, it must do one or more of the following: (1) it can spawn in multiple seasons or multiple years, to increase the variability in its larval dispersal by increasing the variability in the currents its larvae encounter; (2) its larvae can spend less time in the plankton, or through their behavior reduce the distance which the mean currents move them (relative to $L_{\text {diff }}$ ); or, (3) it can have a high reproductive rate, integrated over its entire life. In the coastal marine environment advection is a dominant influence on life. Life histories of organisms must include a combination of these traits that minimize downstream advection by the mean currents or maximize the variability of this advection to retain essential upstream populations.

Acknowledgements. We thank C. Dibacco, B. Gaylord, M. Graham, R. Karlson, R. Strathmann, J. Wares, and 2 anonymous reviewers for helpful reviews of the manuscript and D. Houseman for Eqs. (8) and (9), and for his insight on longevity. We thank F. Lutscher for pointing out the convergence properties of the central limit theorem at the tails of a distribution and the implications this has for retention. We thank B. Hickey and S. Geier from the University of Washington for current meter records from the North Pacific GLOBEC program and J. Fleischbein, A. Huyer and the Oregon State University buoy group for their compilation of historical data used in computing Fig. 6, and the scientists and technicians who took these data. This work was financially supported by the NOAA-Cinemar program at the University of New Hampshire and NSF OCE-0219709. This is GLOBEC contribution No. 280.

\section{LITERATURE CITED}

Beardsley RC, Chapman DC, Brink KH, Ramp SR, Schlitz R (1985) The Nantucket Shoals flux experiment (Nsfe79). 1. A basic description of the current and temperature variability. J Phys Oceanogr 15:713-748

Billingham MR, Reusch TBH, Alberto F, Serrao EA (2003) Is asexual reproduction more important at geographical limits? A genetic study of the seagrass Zostera marina in the Ria Formosa, Portugal. Mar Ecol Prog Ser 265: 77-83

Bird JM, Hodkinson ID (1999) Species at the edge of their range: the significance of the thermal environment for the distribution of congeneric Craspedolepta species (Sternorrhyncha: Psylloidea) living on Chamerion angustifolium (Onagraceae). Eur J Entomol 96:103-109

Brink KH, Limeburner R, Beardsley RC (2003) Properties of flow and pressure over Georges Bank as observed with near-surface drifters. J Geophys Res Oceans 108:DOI 10.1029/2001JC001019

Brown JH, Lomolino MV (1998) Biogeography. Sinauer Associates, Sunderland, MA

Caughley G, Grice D, Barker R, Brown B (1988) The edge of the range. J Anim Ecol 57:771-785

Clarke A (1992) Reproduction in the cold-Thorson revisited. Invertebr Reprod Dev 22:175-184

Crozier L (2003) Winter warming facilitates range expansion: cold tolerance of the butterfly Atalopedes campestris. Oecologia 135:648-656

Davis RE (1985) Drifter observations of coastal surface currents during code-the statistical and dynamical views. J Geophys Res Oceans 90:4756-4772

De Wreede RE, Klinger T (1988) Reproductive strategies in algae. In: Lovett Doust J, Lovett Doust L (eds) Plant reproductive ecology. Oxford University Press, New York, p 267-284

Dixon PS (1965) Perennation, vegetative propogation and algal life histories, with special reference to Asparagopsis and other Ryodophyta. Bot Gothob 3:67-74

Eckert CG (2002) The loss of sex in clonal plants. Evolutionary Ecology 15:501-520

Epifanio CE, Dittel AI, Park S, Schwalm S, Fouts A (1998) Early life history of Hemigrapsus sanguineus, a nonindigenous crab in the Middle Atlantic Bight (USA). Mar Ecol Prog Ser 170:231-238

Fisher RA (1937) The wave of advance of advantageous genes. Ann Eugenics 7:225-369

Gaines SD, Gaylord B, Largier JL (2003) Avoiding current oversights in marine reserve design. Ecol Appl 13:S32-S46

Gaston KJ (2003) The structure and dynamics of geographic ranges. Oxford University Press, Oxford

Gaylord B, Gaines SD (2000) Temperature or transport? Range limits in marine species mediated solely by flow. Am Nat 155:769-789

Grosholz ED (1996) Contrasting rates of spread for introduced species in terrestrial and marine systems. Ecology 77 : 1680-1686

Hetland RD, Signell RP (2005) Modeling coastal current transport in the Gulf of Maine. Deep-Sea Res II 52:2430-2449

Huyer A, Sobey EJC, Smith RL (1979) Spring transition in currents over the Oregon Continental Shelf. J Geophys Res Oceans Atmos 84:6995-7011

Kot M, Lewis MA, van den Driessche P (1996) Dispersal data and the spread of invading organisms. Ecology 77 : 2027-2042

Kundu P (1990) Fluid mechanics. Academic Press, San Diego, CA 
Largier JL (2003) Considerations in estimating larval dispersal distances from oceanographic data. Ecol Appl 13:S71-S89

Lentz SJ (1987) A description of the 1981 and 1982 spring transitions over the northern California shelf. J Geophys Res Oceans 92:1545-1567

Loder JW, Petrie B, Gawarkiewicz G (1998) The coastal ocean off Northeastern North America: a large-scale view. In: Brink KH, Robinson AR (eds) The sea - the global coastal ocean-region studies and syntheses. John Wiley \& Sons, New York, p 125-134

Lutscher F, Pachepsky E, Lewis MA (2005) The effect of dispersal patterns on stream populations. SIAM J Appl Math 65:1305-1327

McDermott JJ (1991) A breeding population of the Western Pacific crab Hemigrapsus sanguineus (Crustacea, Decapoda, Grapsidae) established on the Atlantic coast of North America. Biol Bull (Woods Hole) 181:195-198

Morgan SG (1995) Life and death in the plankton: larval mortality and adaptation. In: McEdward LR (ed) Ecology of marine invertebrate larvae. CRC Press, Boca Raton, FL, p 279-322

Müller K (1982) The colonization cycle of freshwater insects. Oecologia 52:202-207

Pachepsky E, Lutscher F, Nisbet RM, Lewis MA (2005) Persistence, spread and the drift paradox. Theor Popul Biol 67(1):61-73

Pearse JS, Mcclintock JB, Bosch I (1991) Reproduction of Antarctic benthic marine invertebrates - tempos, modes, and timing. Am Zool 31:65-80

Pechenik JA (1999) On the advantages and disadvantages of larval stages in benthic marine invertebrate life cycles. Mar Ecol Prog Ser 177:269-297

Pettigrew NR, Townsend DW, Xue HJ, Wallinga JP, Brickley PJ, Hetland RD (1998) Observations of the Eastern Maine Coastal Current and its offshore extensions in 1994. J Geophys Res Oceans 103:30623-30639

Reitzel AM, Miner BG, McEdward LR (2004) Relationships between spawning date and larval development time for benthic marine invertebrates: a modeling approach. Mar Ecol Prog Ser 280:13-23

Roberts MJ, Riccardo R (1999) A student's guide to analysis of variance. Routledge, London

Shanks AL, Grantham BA, Carr MH (2003) Propagule dispersal distance and the size and spacing of marine reserves. Ecol Appl 13:S159-S169

Shearman RK, Lentz SJ (2003) Dynamics of mean and subtidal flow on the New England shelf. J Geophys Res Oceans 108:3281 DOI 10.1029/2002JC001417

Siegel DA, Kinlan BP, Gaylord B, Gaines SD (2003) Lagrangian descriptions of marine larval dispersion. Mar Ecol Prog Ser 260:83-96

Skellam JG (1951) Random dispersal in theoretical populations. Biometrika 38:196-218

Smith PC, Houghton RW, Fairbanks RG, Mountain DG (2001)
Interannual variability of boundary fluxes and water mass properties in the Gulf of Maine and on Georges Bank: 1993-1997. Deep Sea Res Part II 48:37-70

Southward AJ, Hawkins SJ, Burrows MT (1995) Seventy years observations of changes in distribution and abundance of zooplankton and intertidal organisms in the Western English Channel in relation to rising sea temperature. J Therm Biol 20:127-155

Speirs DC, Gurney WSC (2001) Population persistence in rivers and estuaries. Ecology 82:1219-1237

Stachowicz JJ, Terwin JR, Whitlatch RB, Osman RW (2002) Linking climate change and biological invasions: ocean warming facilitates nonindigenous species invasions. Proc Natl Acad Sci USA 99:15497-15500

Strathmann MF (1987) Reproduction and development of marine invertebrates of the northern Pacific coast. University of Washington Press, Seattle, WA

Strathmann RR (1980) Why does a larva swim so long? Paleobiology 6:373-376

Strathmann RR (1985) Feeding and nonfeeding larval development and life-history evolution in marine invertebrates. Annu Rev Ecol System 16:339-361

Strathmann RR (1990) Why life histories evolve differently in the sea. Am Zool 30:197-207

Strathmann RR, Hughes TR, Kuris AM, Lindeman KC, Morgan SG, Pandolfi JM, Warner RR (2002) Evolution of local recruitment and its consequences for marine populations. Bull Mar Sci 70:377-396

Strub PT, Allen JS, Huyer A, Smith RL, Beardsley RC (1987) Seasonal cycles of currents, temperatures, winds, and sea level over the Northeast Pacific Continental Shelf-35 degrees $\mathrm{N}$ to 48 degrees N. J Geophys Res Oceans 92: $1507-1526$

Swearer SE, Caselle JE, Lea DW, Warner RR (1999) Larval retention and recruitment in an island population of a coral-reef fish. Nature 402:799-802

Swearer SE, Shima JS, Hellberg ME, Thorrold SR and 6 others (2002) Evidence of self-recruitment in demersal marine populations. Bull Mar Sci 70:251-271

Thorson G (1950) Reproductive and larval ecology of marine bottom invertebrates. Biol Rev 25:1-45

Tilburg CE, Reager JT, Whitney MM (2005) The physics of blue crab larval recruitment in Delaware Bay: a model study. J Mar Res 63:471-495

Vance RR (1973) On reproductive strategies in marine benthic invertebrates. Am Nat 107:339-352

Whittick A (1978) The life history and phenology of Callithamnion corymbosum (Rhodophyta: Ceramiaceae) in Newfoundland. Can J Bot 56:2497-2499

Winant CD, Beardsley RC, Davis RE (1987) Moored wind, temperature, and current observations made during coastal ocean dynamics experiments-1 and experiment-2 over the Northern California continental-shelf and upper slope. J Geophys Res Oceans 92:1569-1604 
Appendix 1. Numerical model for formulation and errors

Some of the results presented in this study for semelparous species are found analytically, but the quantitative predictions of the importance of iteroparity and interannual variations of $L_{\text {adv }}$ must be confirmed with a numerical model. The numerical model is a straightforward implementation of the idealized organism described above, a benthic organism with an obligate planktonic stage in an environment with a finite carrying capacity. The habitat in the computer is a 1-dimensional array of settlement sites each of which can hold 1 adult. Each adult produces $N_{\text {fec }}$ larvae which move on average $L_{\text {adv }}$ downstream from its mother, with a SD of this movement of $L_{\text {diff }}$ (both $L_{\text {adv }}$ and $L_{\text {diff }}$ can be functions of the mother's location, and can change with time). If a larva arrives at a site that is occupied by an adult, the larva dies. If several larvae arrive at the same site in the same generation, 1 is randomly chosen as the survivor. In a uniformly settled domain, this would lead to a logistic density dependent population growth rate. Larvae which move out of the domain die. The adults live for $N_{\text {gen }}$ generations, and then die. The larval dispersal kernel in most runs was Gaussian, but results did not change significantly when a top-hat or double-exponential dispersal kernel was used within the limits of validity given in the 'Methods' section of the text. When $L_{\mathrm{adv}}$ changes between generations, this variation is drawn from a Gaussian distribution. The results do not change if it is drawn from a uniform distribution instead. The numerical model was written in MATLAB and Fortran, and is available upon request from the authors.

The numerical model is not a perfect analogue of the idealized problem described in the model and results section. To have an operational simulation model we needed to make a few simplifying changes to the underlying assumptions of the theory/equations. These changes were to make the domain size and habitat availability finite. However, we show that both of these changes have very little effect on model outcomes. First, the model domain is finite while the derivation of Eq. (5) above assumes an infinite domain. However, the finite domain does not have a material effect on the results presented above-all runs shown were run with a domain of twice the size, and the minimum growth needed to allow retention changed by less than $10 \%$. In all cases the model domain is much larger than $L_{\text {adv }}$ and $L_{\text {diff. }}$.

A more subtle limitation in the model arises from the fact that the maximum population density of the larval habitat must be much lower in the numerical model than in the real world, due to our finite computer resources. Because of this, the number of successful larvae per lifetime at low population densities is not exactly $N_{\text {fec }} \times N_{\text {gen }}$, for even when only a single organism inhabits the domain, 2 of its larvae might try to settle in the same location, resulting in the failure of one of them. The importance of this can be monitored by examining the threshold for retention of semelparous organisms, for which we have an analytic solution. For a species which produces 30 potentially successful larvae in its lifetime, the minimum $N_{\text {fec }} \times N_{\text {gen }}$ needed to allow retention is $30 \%$ higher than predicted if there are 250 settlement sites in an stretch of coastline of length $L_{\text {diff }}$. If this same stretch of coastline has 500 settlement sites, the minimum $N_{\text {fec }} \times N_{\text {gen }}$ is $12 \%$ higher than predicted, and if it has 5000 sites, the $N_{\text {fec }} \times N_{\text {gen }}$ is $5 \%$ higher than predicted. We used this latter density of settlement sites $/ L_{\text {diff }}$ in the results presented in the text and figures. Holding $L_{\text {diff }}$ constant, the error increases roughly as square root of $N_{\text {fec }}$ for a given $N_{\text {gen }}$. The ratio of settlement sites to $L_{\text {diff }}$ is inconsequential for most oceanic species; for example, for a barnacle whose $L_{\text {diff }}$ is only $10 \mathrm{~km}$, the number of potential settling sites in a distance $L_{\text {diff }}$ along a rocky coast would be much greater than the 5000 in the model.

The numerical model has an additional shortcoming due to its finite domain size when $L_{\mathrm{adv}}$ is allowed to vary randomly in time. A randomly varying $L_{\text {adv }}$ has some probability of exceeding the value which allows retention for some finite amount of time. In any finite domain with a fluctuating $L_{\text {adv }}$, there will eventually be a period of anomalously high $L_{\mathrm{adv}}$ which drives the species extinct in the domain. The closer the species is to failing to satisfy Eq. 6, the more rapidly this will occur because the smaller the sustained anomaly in $L_{\text {adv }}$ must be to drive the species extinct. Likewise, the smaller the numerical model domain, the more likely it is that a species will go extinct in a finite time, for an anomalously high $L_{\text {adv }}$ must be sustained for a smaller time to drive the species to extinction. This can be seen clearly in the semelparous species in Fig. 5. As the variability increases, the growth rate needed to retain the species in the finite domain increases slightly. We confirmed that this was an artifact due to the finite domain by re-running the model in a domain half as large; the increase in growth needed to allow retention at high levels of variability was more than doubled.
Editorial responsibility: Ron Karlson (Contributing Editor), Newark, Delaware, USA
Submitted: April 12, 2005; Accepted: September 5, 2005 Proofs received from author(s): March 4, 2006 